\title{
Reduction of Kemi chromite with methane
}

\author{
by M. Leikola*, P. Taskinen*, and R.H. Eric*†
}

\section{Synopsis}

Kemi chromite ore from Finland was reduced in $\mathrm{CH}_{4}-\mathrm{H}_{2}$ gas mixtures at temperatures from $1100^{\circ}$ to $1350^{\circ} \mathrm{C}$. Experimental variables were time, temperature, and the $\mathrm{CH}_{4}$ content of the gas mixture. The phases in reacted samples were determined by XRD and quantitative phase analysis was performed using the Rietveld method. Particle morphology and phase compositions were determined using SEM and EDS analysis. Reduction proceeded through a shrinking core model in two stages. In the first stage, hydrogen and carbon from the cracking of methane reduced the iron and some chromium to carbides. The chromium in the remaining spinel was reduced during the second stage. Iron was essentially reduced in full after 30 minutes when the temperature reached $1300^{\circ} \mathrm{C}$, and at $1350^{\circ} \mathrm{C}$ it was completely reduced within 20 minutes. At this highest temperature, all of the chromium was eventually reduced, the residue consisting of aluminum and magnesium oxides with varying amounts of silica. At the surface of the particle iron and chromium, together with carbon, formed two alloys, an iron-dominated and a chromium-based one. The iron-based phase was partially molten at the higher temperatures. At $1300^{\circ} \mathrm{C}$ and $1350^{\circ} \mathrm{C}$ the metallization was complete. Reduction of Kemi chromite with a $\mathrm{CH}_{4}-\mathrm{H}_{2}$ mixture is judged as highly efficient, since high of reduction extents could be reached faster at lower temperatures compared to carbothermic reduction. This is attributed to the very high activity of carbon (way above $1.0)$ due to the cracking of methane into hydrogen and carbon at around $550^{\circ} \mathrm{C}$ in the presence of a solid phase.

Keywords

chromite, solid-state prereduction, methane, hydrogen.
Reduction of the iron and chromium oxide components is needed to produce metallic ferrochrome. Currently, this is done in electric submerged arc furnaces (SAFs) using coke as the reductant. This requires high temperatures and therefore the furnace consumes a lot of electricity (Basson and Daavittila, 2013). It is possible to prereduce the chromite ore pellets in solid form before charging them into the SAF. This procedure lowers the electricity consumption in the SAF, due to the lesser extent of the Boudouard reaction.

The solid-state prereduction can be performed by utilizing carbon (Niayesh and Dippenaar, 1992; Kekkonen, Xiao, and Holappa, 1995), a methane-hydrogen mixture (Anacleto and Ostrovski, 2004; de Campos and Eric, 2006), or hydrogen (Arvanitidis, 1996). Reduction of chromite with a methanehydrogen gas mixture is the most energyefficient, since reduction takes place at a lower temperature (Anacleto and Ostrovski, 2004; de Campos and Eric, 2006). This is due to the high activity of the carbon (Anacleto and Ostrovski, 2004). At temperatures above $550^{\circ} \mathrm{C}$, due to the cracking of methane, the activity of precipitating carbon starts to rise exponentially, well exceeding 1.0 (with respect to pure solid graphite, which would have unit activity). This is well known thermodynamically and is due to the fact the precipitated carbon is not yet in graphitic form (Taskinen, Fabritius, and Eric, 2014). The reaction mechanism is based on the adsorption of methane onto the active oxide surface. After adsorption, the methane cracks into hydrogen gas and solid carbon as described in Equations [1]-[6]:

* Department of Chemical and Metallurgical Engineering, Aalto University, Espoo, Finland.

+ School of Chemical and Metallurgical Engineering, Johannesburg, South Africa

(1) The Southern African Institute of Mining and Metallurgy, 2018. ISSN 2225-6253. This paper was first presented at the INFACON XV:

International Ferro-Alloys Congress, 25-28

February 2018, Century City Conference Centre and Hotel, Cape Town, South Africa. 


\section{Reduction of Kemi chromite with methane}

$$
\begin{aligned}
& \mathrm{CH}_{4}(\mathrm{~g}) \rightarrow \mathrm{CH}_{4}(\mathrm{ad}) \\
& \mathrm{CH}_{4}(\mathrm{ad}) \rightarrow \mathrm{CH}_{3}(\mathrm{ad})+\mathrm{H}(\mathrm{ad}) \\
& \mathrm{CH}_{3}(\mathrm{ad}) \rightarrow \mathrm{CH}_{2}(\mathrm{ad})+\mathrm{H}(\mathrm{ad}) \\
& \mathrm{CH}_{2}(\mathrm{ad}) \rightarrow \mathrm{CH}(\mathrm{ad})+\mathrm{H}(\mathrm{ad}) \\
& \mathrm{CH}(\mathrm{ad}) \rightarrow \mathrm{C}(\mathrm{ad})+\mathrm{H}(\mathrm{ad}) \\
& 2 \mathrm{H}(\mathrm{ad}) \rightarrow \mathrm{H}_{2}(\mathrm{~g})
\end{aligned}
$$

resulting in the overall reaction of methane adsorption on the oxide's active surface as in Equation [7]

$$
\mathrm{CH}_{4}(\mathrm{~g}) \rightarrow \mathrm{C}(\mathrm{ad})+2 \mathrm{H}_{2}(\mathrm{~g})
$$

The overall reaction for reduction of chromium by methane oxide can be represented as:

$$
3 \mathrm{Cr}_{2} \mathrm{O}_{3}(\mathrm{~S})+13 \mathrm{CH}_{4}(\mathrm{~g}) \rightarrow 2 \mathrm{Cr}_{3} \mathrm{C}_{2}(\mathrm{~S})+9 \mathrm{CO}+26 \mathrm{H}_{2}(\mathrm{~g})
$$

This reaction mechanism has been proposed for both pure chromium oxide (Anacleto and Ostrovski, 2004) and natural chromite (de Campos and Eric, 2006). In the present work, the aim was to investigate the characteristics of methane reduction for a specific chromite mined in Kemi, Finland.

\section{Materials and methods}

Chromite ore from Kemi has a relatively low $\mathrm{Cr} / \mathrm{Fe}$ ratio, but due to the mine's proximity to a stainless steel plant, it is nevertheless a profitable deposit for mining (Huovinen, 2007). XRD analysis of the received concentrate indicated that $\mathrm{Mg}-\mathrm{Al}-\mathrm{Cr}-\mathrm{Fe}$ spinel was the main mineral in the sample, with very little separate silica phase. A chemical analysis of the raw material is presented in Table I.

The particle size distribution of the concentrate is shown

\begin{tabular}{|c|c|c|c|c|c|c|c|c|c|}
\hline \multicolumn{10}{|c|}{$\begin{array}{l}\text { Table I } \\
\text { Chemical analysis (wt\%) of chromite ore } \\
\text { concentrate used in this study }\end{array}$} \\
\hline $\mathrm{Mg}$ & Al & $\mathrm{Ca}$ & $\mathrm{Ti}$ & $\mathrm{Cr}$ & Crmet & $\mathrm{Fe}$ & Fe met & $\mathrm{SiO}_{2}$ & Total \\
\hline 6.5 & 6.6 & 0.41 & 0.28 & 29.9 & 0.02 & 17.6 & 0.21 & 3.4 & 64.71 \\
\hline
\end{tabular}
in Figure 1. The analysis was done using a Mastersizer 2000 from Malvern Instruments. Five measurements were conducted using 4 bar dispersion pressure and Fraunhofer approximation for the calculations.

The reduction experiments were conducted on a loose bed of chromite concentrate powder in a closed, horizontal-tube electric furnace. One gram of Kemi chromite concentrate was

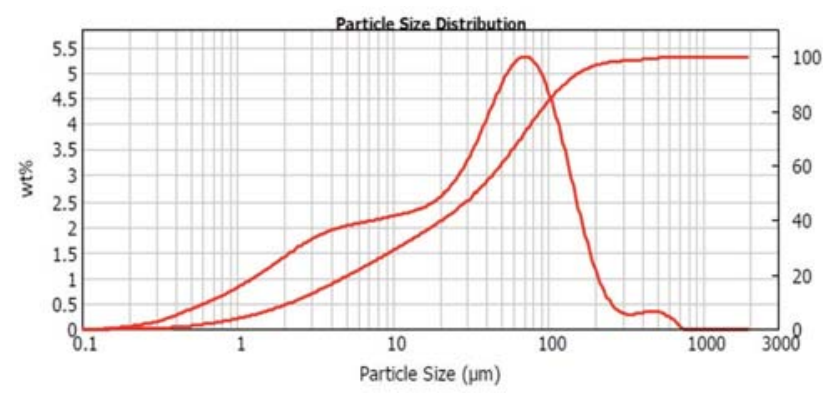

Figure 1-Particle size distribution of the chromite concentrate reduced for various time intervals $(10,20,30,60,90$, and 120 minutes) in controlled atmospheres of varying $\mathrm{CH}_{4}-\mathrm{H}_{2}$ contents $\left(10,20\right.$, and $\left.30 \mathrm{vol} \% \mathrm{CH}_{4}\right)$. Gas flow through the furnace was kept constant at $1 \mathrm{l} / \mathrm{min}$. The reduction temperatures were $1100,1200,1300$, and $1350^{\circ} \mathrm{C}$. Argon was used for a reference test and as an inert gas for purging the furnace. The gas components used were instrumental argon (Ar 99.999\%), industrial hydrogen ( $\left.\mathrm{H}_{2} 99.99 \%\right)$, and industrial methane $\left(\mathrm{CH}_{4} 99.5 \%\right)$, all supplied by AGA, a member of the Linde Group. Alumina crucibles were used as sample holders for the chromite concentrate.

Phase characterization of the reduced samples was done by X-ray diffraction (XRD), using an X'pert PRO by PANalytical. Quantitative phase analysis was by the Rietveld method (Hem et al., 2009) with PANalytical's X'Pert HighScore Plus program. SEM-EDS analysis was performed using a LEO model 1450 VP and Oxford Instruments INCA software. The amount of carbon in the samples was determined using an Eltra CS-2000 S/C analyser.

The isothermal sections and liquidus contour diagrams of the C-Cr-Fe system were calculated with MTDATA software (Davies et al., 2002) using the iron-base alloy database TCFe (National Physical Laboratory, 2015). The calculation included 21 possible condensed phases. The gas phase was excluded because it is of only minor importance in the calculations and phase equilibria of the system.

\section{Results and discussion}

\section{Reduction mechanism}

SEM analysis clearly showed that an outer layer of metal carbides formed, with inner layers of partially reduced chromite. Beneath the partially reduced regions, there was an unreacted core with the same composition as the raw material. This is referred to as a shrinking core mechanism and it has been observed previously for chromite reduction with methane (de Campos and Eric, 2006). The shrinking core was observed throughout the experimental series and it appeared to form in two stages. In the first stage, the iron is completely reduced along with part of the chromium. In the second stage, the rest of the chromium is reduced completely.

An example of the first reduction stage can be seen in Figure 2, where the outer layer is almost white, the partially reduced area is a darker gray, and the unreacted core is a lighter gray. Reduction was carried out at $1100^{\circ} \mathrm{C}$, with 10 vol\% $\mathrm{CH}_{4}$, for 20 minutes. EDS analyses were performed on the points indicated in the image. The compositional trends are shown in Figure 3. An EDS analysis of the raw material is also illustrated (dashed lines) in order to demonstrate that the core is, in fact, unreacted chromite ore. Small amounts of calcium and titanium are excluded from the data for clarity reasons.

Spectra 4 to 7 are taken from the unreacted core. Their compositions match relatively well with the dashed lines representing the raw material before reduction. Spectrum 3 , which falls inside the darker grey area, has a significantly lower iron content, indicating that iron has been reduced to the metallic form and diffused to the surface, represented by spectrum 1. The amounts of chromium and magnesium are higher in spectrum 3, because most of the iron has been removed from this area. Spectrum 1 is on the white outer rim 


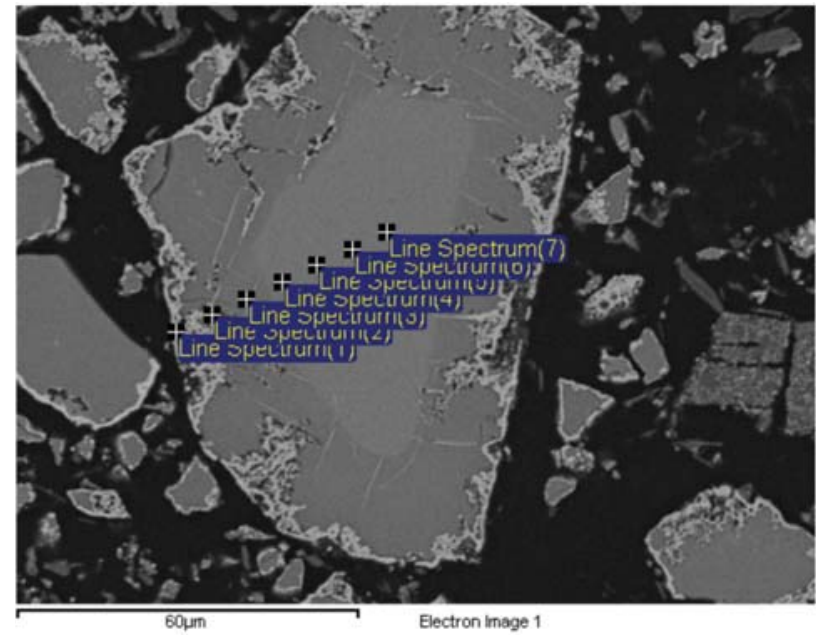

Figure 2-SEM micrograph of a sample reduced at $1100^{\circ} \mathrm{C}$, using 10 vol $\% \mathrm{CH}_{4}$, for 20 minutes

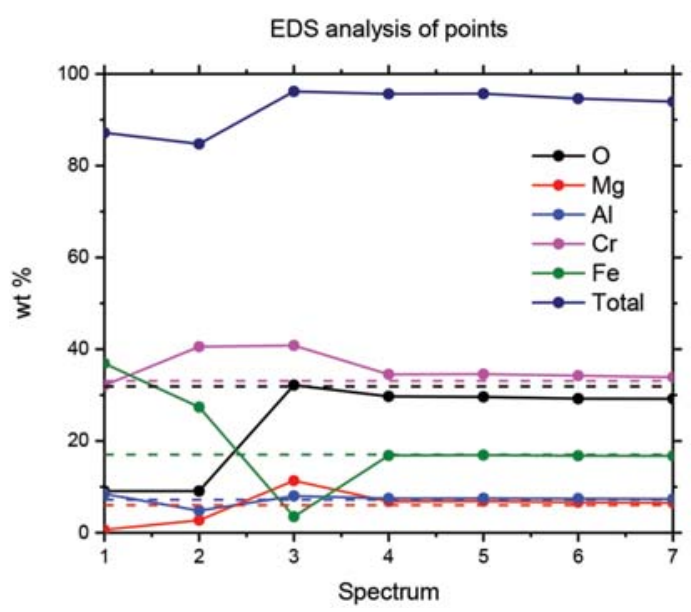

Figure 3-EDS analysis of the particle in Figure 2. Solid lines represent the analysis results, and dashed lines indicate the composition of the raw material

of the particle. It consists mostly of iron and chromium, with the oxygen content considerably lower than in other regions. This indicates that the outer layer is mostly metallic chromium and iron.

Figure 4 and Table II show the SEM micrograph and EDS analysis for a particle in the second stage of the shrinking core process, where iron has been almost completely reduced and chromium reduction is advancing. Table II shows the average EDS analysis results for the white areas, dark grey rims around the white beads, and central areas. Reduction was performed at $1300^{\circ} \mathrm{C}$, with $30 \mathrm{vol} \% \mathrm{CH}_{4}$, for 120 minutes. The small amounts of calcium and titanium were again excluded from the data for clarity reasons.

The iron content is very low $(<1 \mathrm{wt} \%)$ outside the white areas. The chromium concentration here behaves more like the iron did in the sample depicted in Figure 2, first decreasing, but then increasing towards the centre. This indicates that almost all the iron has been reduced and has accumulated in the white areas as carbides, while chromium reduction is advancing towards the core of the particle.
It can be seen from Table II that the bright areas in Figures 2-4 consist mostly of iron and chromium. However, the samples for SEM analysis were coated with carbon and therefore the EDS analysis excludes all carbon. The total mass of material is lower in the lighter areas, and therefore it can be concluded that there is also carbon in the light areas on the edges of the particles. This indicates that iron and chromium might form carbides as they are reduced, which was observed by Soykan, Eric, and King (1991) with solid carbon as the reductant.

Figures 2 and 4 both show that the reduction also advances within the particle along cracks that form along the crystalline structure of the chromite spinel. This has also been observed in other studies (de Campos and Eric, 2006; Soykan, Eric, and King, 1991; Perry, Finn, and King, 1988).

In addition to the particles reducing through the shrinking core mechanism, collapsed particles were present in all the samples. The shrinking core mechanism was observed to be dominant in the earlier stages of the reduction. As reduction progresses, the particles start to collapse, resulting in reduction also inside the particle and not just on the outer surface, and in small cracks inside the particle. This is evident in Figure 5, which compares the particles reduced at $1300^{\circ} \mathrm{C}$ with varying methane concentrations for $10 \mathrm{~min}$ and

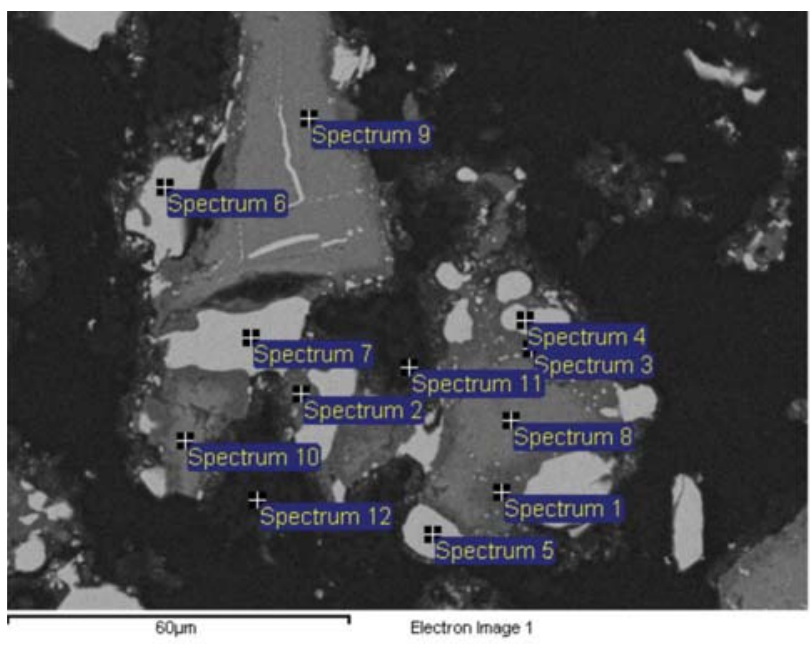

Figure 4-SEM micrograph of a sample reduced at $1300^{\circ} \mathrm{C}$, using 30 vol $\% \mathrm{CH}_{4}$, for 120 minutes

Table II

EDS analyses of different phases in Figure 4 (wt \%)

\begin{tabular}{l|c|c|c|}
\hline Element & White & Dark grey & Centre \\
\hline $\mathrm{O}$ & 0.43 & 35.55 & 30.50 \\
$\mathrm{Mg}$ & 0.00 & 19.94 & 12.50 \\
$\mathrm{Al}$ & 0.00 & 18.62 & 9.45 \\
$\mathrm{Si}$ & 0.00 & 5.92 & 0.06 \\
$\mathrm{Ca}$ & 0.00 & 0.65 & 0.00 \\
$\mathrm{Ti}$ & 0.00 & 0.22 & 0.86 \\
$\mathrm{Cr}$ & 44.62 & 6.11 & 36.34 \\
$\mathrm{Fe}$ & 38.48 & 0.86 & 0.76 \\
\hline Total & 83.52 & 87.86 & 90.32 \\
\hline
\end{tabular}




\section{Reduction of Kemi chromite with methane}

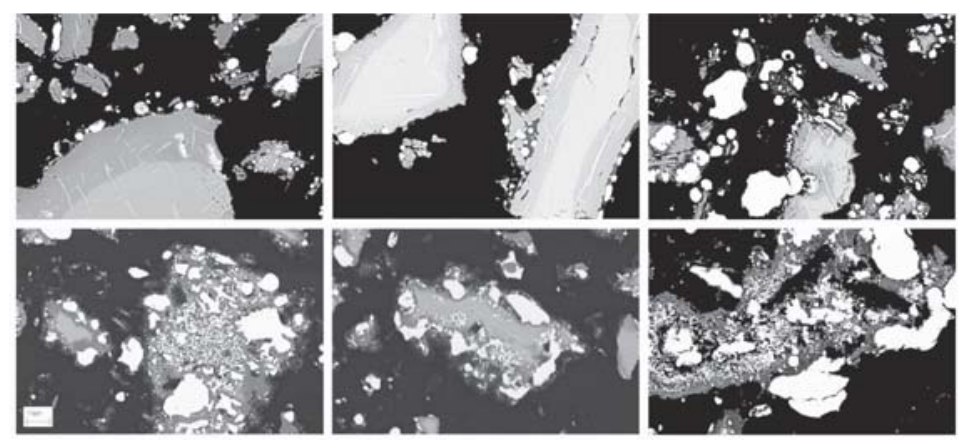

Figure 5-SEM micrographs of samples reduced for 10 minutes (upper row) and 90 minutes (lower row). The reduction was done at $1300^{\circ} \mathrm{C}$ with 10,20 , and $30 \mathrm{vol} \% \mathrm{CH}_{4}$ (left to right)

90 minutes' reduction time. The upper row of micrographs is with 10 minutes' reduction time and the lower is with 90 minutes. The methane contents of the gas mixture are 10, 20, and $30 \mathrm{vol} \%$. This illustrates a change in the reduction mechanism with reduction time.

\section{Iron metallization}

The first stage of reduction advances significantly in the first 10 minutes at all temperatures and with all $\mathrm{CH}_{4}-\mathrm{H}_{2}$ mixtures. A micrograph and EDS analysis of the reduced areas in the sample reduced with $10 \mathrm{vol} \% \mathrm{CH} 4$ at $1100^{\circ} \mathrm{C}$ for 10 minutes are shown in Figure 6. The white reaction product layers on the edges of the particles are clearly visible.

At $1300^{\circ} \mathrm{C}$ practically all the iron was reduced and had diffused into the metallic phase (white areas). Figure 7 compares two micrographs of samples reduced at $1300^{\circ} \mathrm{C}$ with 10 vol\% $\mathrm{CH}_{4}$ for 20 and 30 minutes. Table III shows the EDS analyses of the grey areas in the centre of the particles.

After 20 minutes, the centre of the particle still contains unreduced material (in spectra 3 to 5), where the iron content is around $15 \mathrm{wt} \%$, which is very close to the $17 \mathrm{wt} \%$ of the raw material. However after 30 minutes' reduction time, this phase is no longer detectable and the iron content throughout the particle's grey centre is around $1 \mathrm{wt} \%$. The same phenomenon occurs at $1300^{\circ} \mathrm{C}$ regardless of the methane content used. When the temperature increases to $1350^{\circ} \mathrm{C}$, the unreacted phase is barely detectable after 20 minutes' reduction time.

\section{Chromium metallization}

Generally, the iron-depleted, but still chromium-rich, intermediate phase disappeared at $1350^{\circ} \mathrm{C}$ with a reduction time of 60 minutes or more and a $\mathrm{CH}_{4}$ content of 10 or 20 vol\%. With 30 vol\% $\mathrm{CH}_{4}$, reduction for 30 minutes resulted in the disappearance of the phase, indicating that full reduction was achieved. A typical micrograph and EDS analysis of the samples reduced at $1350^{\circ} \mathrm{C}$ for 90 minutes are shown in Figure 8 and Table IV. Only two phases remain in the particle; the light grey areas of iron-chromium carbide and grey areas consisting of $\mathrm{Mg}$ - $\mathrm{Al}$ spinel with some $\mathrm{Si}, \mathrm{Ca}$, and traces of $\mathrm{Fe}$ and $\mathrm{Cr}$.

Full chromite reduction at $1350^{\circ} \mathrm{C}$ was also supported by the XRD analyses and Rietveld calculations. The chromite concentrations in samples reduced at $1350^{\circ} \mathrm{C}$ are presented in Figure 9. Utilizing 20 vol\% methane resulted in faster reduction than 30 vol\% methane. This could be due to more

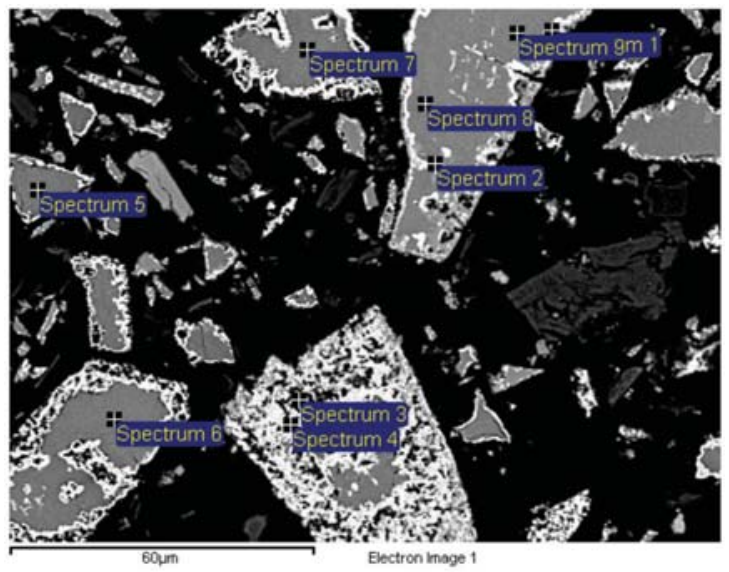

Figure 6-SEM micrograph of a sample reduced at $1100^{\circ} \mathrm{C}$ with $10 \mathrm{vol} \%$ $\mathrm{CH}_{4}$ for 10 minutes
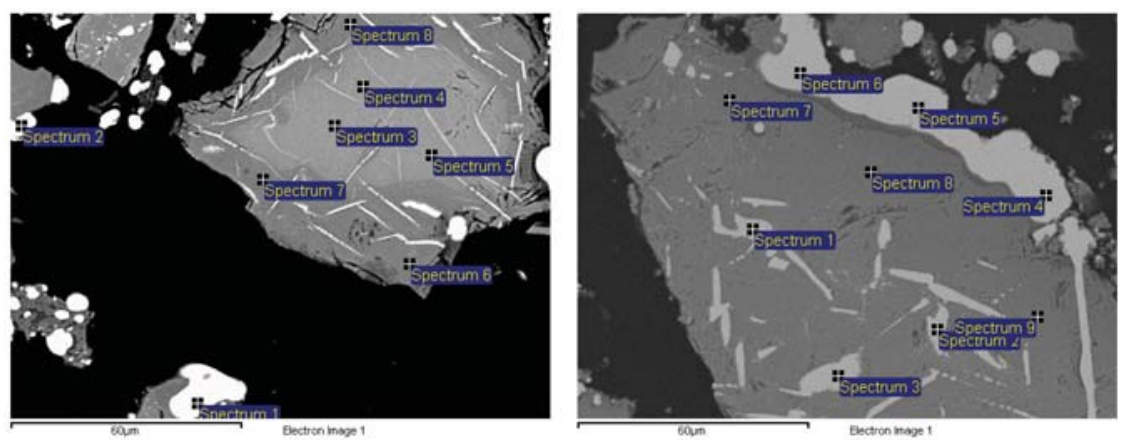

Figure 7-SEM micrographs of samples reduced at $1300^{\circ} \mathrm{C}$ using $10 \mathrm{vol} \% \mathrm{CH}_{4}$, for 20 minutes (left) and 30 minutes (right) 


\section{Reduction of Kemi chromite with methane}

\begin{tabular}{|c|c|c|c|c|c|c|c|}
\hline \multicolumn{8}{|l|}{ Table III } \\
\hline \multicolumn{8}{|c|}{$\begin{array}{l}\text { EDS analyses (wt \%) of samples reduced at } 1300^{\circ} \mathrm{C} \\
\text { with } 10 \mathrm{vol} \% \mathrm{CH}_{4}\end{array}$} \\
\hline $\begin{array}{l}\text { Spectrum } \\
20 \mathrm{~min}\end{array}$ & 0 & Mg & Al & $\mathrm{Ti}$ & $\mathrm{Cr}$ & $\mathrm{Fe}$ & Total \\
\hline Spectrum 3 & 29.79 & 6.84 & 7.87 & 0.22 & 33.78 & 15.86 & 94.36 \\
\hline Spectrum 4 & 29.44 & 6.73 & 7.68 & 0.28 & 33.57 & 15.73 & 93.43 \\
\hline Spectrum 5 & 29.15 & 6.86 & 7.61 & 0.29 & 33.79 & 15.39 & 93.09 \\
\hline Spectrum 6 & 32.79 & 12.50 & 8.36 & 0.39 & 40.15 & 0.79 & 94.98 \\
\hline Spectrum 7 & 33.88 & 12.50 & 8.88 & 0.31 & 39.50 & 2.24 & 97.33 \\
\hline Spectrum 8 & 31.52 & 12.17 & 8.44 & 0.31 & 40.16 & 1.00 & 93.60 \\
\hline \multicolumn{8}{|l|}{$30 \mathrm{~min}$} \\
\hline Spectrum 7 & 30.68 & 10.14 & 11.93 & 0.45 & 36.11 & 1.34 & 90.65 \\
\hline Spectrum 8 & 31.37 & 9.96 & 11.93 & 0.50 & 35.68 & 0.91 & 90.35 \\
\hline Spectrum 9 & 30.62 & 9.45 & 12.15 & 0.35 & 35.38 & 1.06 & 89.02 \\
\hline
\end{tabular}

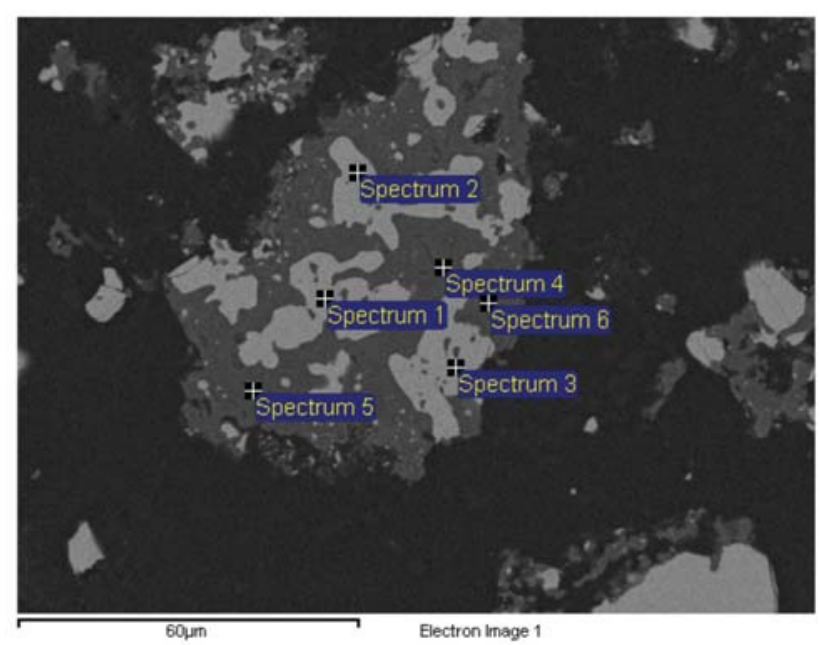

Figure 8-SEM micrograph of a sample reduced at $1350^{\circ} \mathrm{C}$ with 20 vol\% $\mathrm{CH}_{4}$ for 90 minutes

Table IV

EDS analyses (wt\%) of a sample reduced at $1350^{\circ} \mathrm{C}$ with 20 vol\% $\mathrm{CH}_{4}$ for 90 minutes

\begin{tabular}{|l|c|c|c|c|c|c|c|c|}
\hline Spectrum & $\mathbf{0}$ & $\mathbf{M g}$ & $\mathbf{A l}$ & $\mathbf{S i}$ & $\mathbf{C a}$ & $\mathbf{C r}$ & $\mathbf{F e}$ & Total \\
\hline Spectrum 1 & & & & & & 57.15 & 26.10 & 83.25 \\
Spectrum 2 & & & & & & 56.28 & 25.26 & 81.55 \\
Spectrum 3 & & & & & & 56.72 & 26.03 & 82.75 \\
Spectrum 4 & 40.94 & 28.77 & 6.30 & 15.56 & 2.33 & 0.81 & & 94.71 \\
Spectrum 5 & 43.92 & 24.16 & 20.59 & 7.69 & 1.56 & 2.28 & 0.55 & 101.16 \\
Spectrum 6 & 39.36 & 30.97 & 3.02 & 14.87 & 2.45 & 0.51 & & 91.18 \\
\hline
\end{tabular}

solid carbon accumulating on the surface of the sample at 30 vol\% methane, hindering diffusive gas flow to the chromite surface.

\section{Iron- and chromium-based alloys}

During the second stage of reduction, the fraction of chromium in the reduced phase increases as the process advances. More chromium accumulates in the reduced (white) metallic areas, until the phase becomes saturated with it. At this point a chromium-based phase starts to form within the reduced phase. The two phases are visible in several samples and were analysed where the surface areas were large enough for EDS analysis. Figure 10 shows a SEM micrograph in which the two phases are clearly

distinguishable at the right-hand side of the image. At the left-hand side, the phases have begun to separate, but the surface of the particle was not suitable for EDS analysis. This image shows how the separation of the two phases progresses through growth of smaller formations towards larger phase areas as diffusion progresses. The EDS analyses for the two phases in the right-hand side particle are listed in Table V.

The darker grey phase consists mostly of chromium and the brighter grey phase contains mostly iron. Therefore, the darker phase is the new, chromium-based alloy. In both examples, the brighter phase has a higher total analysis, which indicates that the darker phase contains more carbon than the bright phase. A rough evaluation of the $\mathrm{Cr}-\mathrm{Fe}-\mathrm{C}$ ternary plot at $1300^{\circ} \mathrm{C}$, presented in Figure 11, indicates that the iron-based phase is partly molten, but the chromiumbased phase is completely solid. The sharp corners of the areas of chromium-based alloy in Figure 10 also confirm that the phase is formed as a solid. The composition of the ironbased phase is depicted with green lines in Figure 11, and that of the chromium-based phase with red lines.

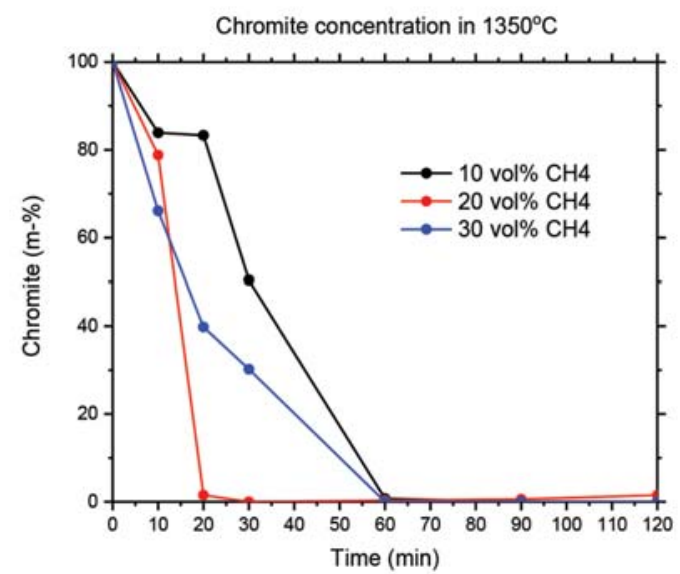

Figure $9-$ Chromite concentration after reduction at $1350^{\circ} \mathrm{C}$, from XRD analyses and Rietveld calculations

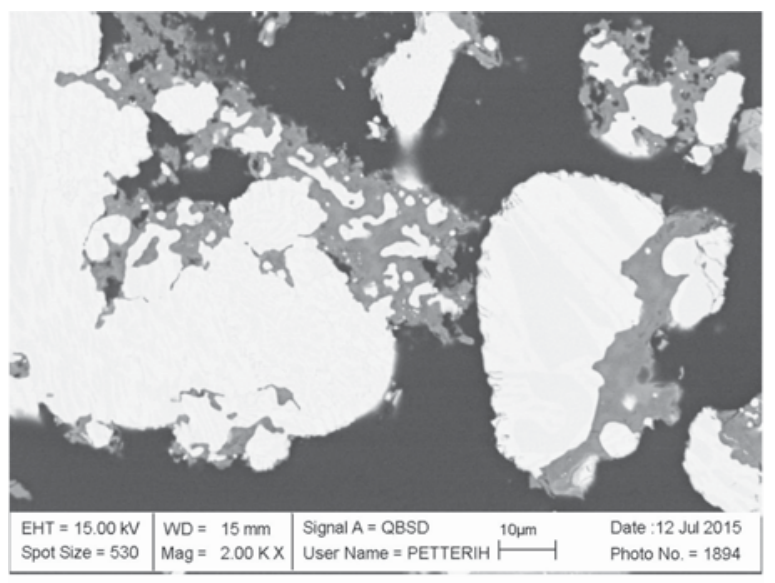

Figure $10-\mathrm{SEM}$ micrograph of a sample reduced at $1350^{\circ} \mathrm{C}$ with 30 vol $\% \mathrm{CH}_{4}$ for 20 minutes 


\section{Reduction of Kemi chromite with methane}

\section{Table $V$ \\ EDS analyses of the two reduced phases at the right-hand side in Figure 10 (wt\%)}

\begin{tabular}{l|c|c|c|c|c}
\hline Phase & $\mathbf{0}$ & $\mathbf{S i}$ & $\mathbf{C r}$ & Fe & Total \\
\hline Bright phase 1 & & 3.13 & 35.35 & 50.50 & 88.99 \\
Bright phase 2 & & 3.39 & 35.78 & 50.24 & 89.40 \\
Dark phase 1 & 0.52 & & 70.22 & 10.33 & 80.55 \\
Dark phase 2 & & & 65.80 & 15.16 & 81.48 \\
\hline Average & & & & & \\
\hline Bright phase & & 3.26 & 35.57 & 50.37 & 89.20 \\
Dark phase & 0.26 & & 68.01 & 12.75 & 81.02 \\
\hline
\end{tabular}

The compositions of the phases in Figure 11 were calculated as an average from all the analyses of the two phases throughout the samples where they were present. Carbon was then assumed to balance the total to $100 \%$, but it should be noted that some silica remains in the iron-based phase, and a very small amount of oxygen is present at some of the analysis points. Also, the ternary plot represents a system in equilibrium, but all the obtained results are from systems that most probably are not in equilibrium, but at a stage of transformation. The illustration is therefore just an approximation of a more complex system.

\section{Summary and conclusions}

Chromite concentrate from the Kemi deposit in Finland was reduced in $\mathrm{CH}_{4}-\mathrm{H}_{2}$ atmospheres. Altogether 72 experiments were conducted with three variables: temperature, time, and the content of methane in the feed gas mixture. The reduction temperatures were $1100^{\circ}, 1200^{\circ}, 1300^{\circ}$, and $1350^{\circ} \mathrm{C}$ and the reduction times $10,20,30,60,90$, and 120 minutes. Three methane contents were used; 10,20 , and $30 \mathrm{vol} \%$, with the balance $\mathrm{H}_{2}$.

The reduction was observed to proceed mainly through a shrinking core mechanism in two stages. In the first stage, carbon from the cracking of methane reduces the iron and some chromium to carbides. After this, and partly overlapping with the first stage, a second stage of reduction begins, in which the chromium in the remaining spinel is reduced. The second reduction stage takes place at $1200^{\circ} \mathrm{C}$ and above.

Iron was essentially completely reduced after 30 minutes at $1300^{\circ} \mathrm{C}$. As the temperature was increased to $1350^{\circ} \mathrm{C}$, the iron was almost completely reduced from the chromite after 20 minutes. At the highest temperature, $1350^{\circ} \mathrm{C}$, all of the chromium was eventually reduced after 30-60 minutes, resulting in residual aluminum and magnesium oxides with varying amounts of silica being left from the original Kemi chromite. As chromium reduction proceeded, two separate metallic phases were formed in the reduced areas, one ironbased and one chromium-based.

Metallization was observed to start immediately after the chromite was exposed to $\mathrm{CH}_{4}-\mathrm{H}_{2}$ mixtures, as chromite reduction to metal was observable after only 10 minutes of reduction time. At temperatures of $1300^{\circ} \mathrm{C}$ and $1350^{\circ} \mathrm{C}$, metallization was completed within the duration of the experiments, as only very small amounts of iron and

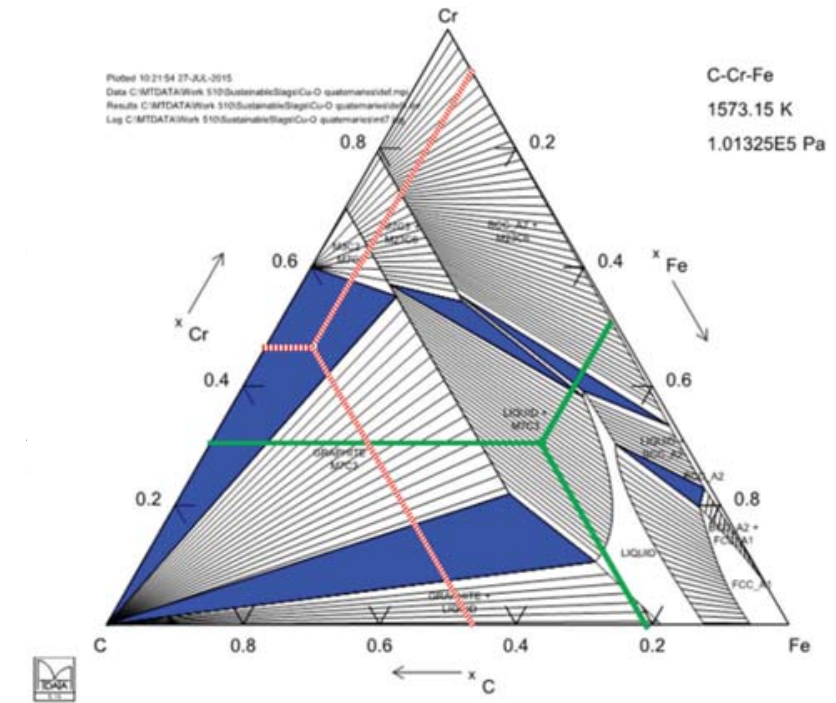

Figure $11-\mathrm{Fe}-\mathrm{Cr}-\mathrm{C}$ ternary plot at $1300^{\circ} \mathrm{C}$ (mol fraction). Composition of the iron-based (bright) phase is illustrated in green, and that of the chromium-based (darker) phase in red

\section{References}

AnAcleto, N. and Ostrovski, O. 2004. Solid-state reduction of chromium oxide by methane-containing gas. Metallurgical and Materials Transactions $B$, vol. 35, no. 4. pp. 609-615.

Arvanitidis, I., Artin, C., Claeson, P., Jacobsson, H., Johansson, P., Rassmus, J., and Swartuing, D. 1996. Study of the kinetics of reduction of iron chromate by hydrogen. Scandinavian Journal of Metallurgy, vol. 25, no. 4. pp. 141-147.

Basson, J. and DaAvitTILA, J. 2013. High carbon ferrochrome technology Handbook of Ferroalloys. Gasik, M.I. (ed.). Elsevier. Chapter 9. pp. 317-363.

De CAmpos, M. and ERIC, R.H. 2006. Reduction behaviour of chromite in the presence of a hydrocarbon gas. Proceedings of the Sohn International Symposium. Advanced Processing of Metals and Materials. Vol. 1. Wiley.

Davies, R.H., Dinsdale, A.T., Gisby, J.A., Robinson, J.A.J., and Martin, S.M. 2002. MTDATA - Thermodynamic and phase equilibrium software from the National Physical Laboratory. Calphad, vol. 26, no. 2. pp. 229-271.

Hem, S.R., Louw, J.D. DE V., GATeShKi, M., GöSKe, J., RindBÆK LARSEn, O., and STRANGEWAYS, J. 2009. Sample preparation for quantitative Rietveld analysis, phase identification and XRF in one step: automated sample preparation by Centaurus. Proceedings of the 7th International Heavy Minerals Conference. Southern African Institute of Mining and Metallurgy, Johannesburg. pp. 49-56.

Huovinen, I. 2007. Kemin kromiitin $\mathrm{Cr} / \mathrm{Fe}$-suhde kromiitin raekoon funktiona Pohjois-Viian, Elijärven ja Elijärven E-malmioissa. Pro gradu, Department of Geosciences, University of Oulu. 104 pp.

KeкKоnen, M., XiAo, Y., and Holappa, L. 1995. Kinetic study on solid state reduction of chromite pellets. Proceedings of the 7th International Ferroalloys Congress (INFACON 7), Trondheim, Norway. Tveit, H., Tuset, J.K., and Page, I.G. (eds). Norwegian Ferroalloy Producers Research Organization (FFF). pp. 351-360.

LYAKISHEV, N.P. and GASIK, M.I. 1998. Metallurgy of Chromium. 1st edn Allerton Press, New York.

MuRThY, Y.R., TRIPATHY, S.K., and KuMAR, C.R. 2011. Chrome ore beneficiation challenges \& opportunities - A review. Minerals Engineering, vol. 24, no. 5. pp. 375-380.

National Physical Laboratory, 2015. MTDATA - Databases. http://www.npl.co.uk/science-technology/mathematics-modelling-andsimulation/mtdata/databases/ [accessed 13 August 2015].

NiAYESH, M.J. and DipPENAAR, R.J. 1992. The solid-state reduction of chromite. Proceedings of INFACON 6, Cape Town. South African Institute of Mining and Metallurgy, Johannesburg. pp. 57-63.

Perry, K.P.D., FinN, C.W.P., and KING, R.P. 1988. An ionic diffusion mechanism of chromite reduction. Metallurgical Transactions B, vol. 19, no. 4. pp. 677-684.

SOYKAN, O., ERIC, R.H., and KING, R.P. 1991. The reduction mechanism of a natural chromite at $1416^{\circ} \mathrm{C}$. Metallurgical Transactions B, vol. 22B. pp. 53-63.

TASkinen, P., FAbritius, T., and ERIC, R.H. 2014. A new FiDiPro project: Sustainable production of ferroalloys. Materia, vol. I, no. 5. pp. 46-50. 